\title{
Answer to a Quiz: Electrocardiogram on page 163 and case discussion
}

\section{Correct answer: E - Atrioventricular (AV) block II degree, advanced}

The main characteristic of the first-degree AV block is ventricles, but with some delay and interval $P Q$ is that all $\mathrm{P}$ waves are conducted via AV node to prolonged - more than 200 ms (Fig. 1).

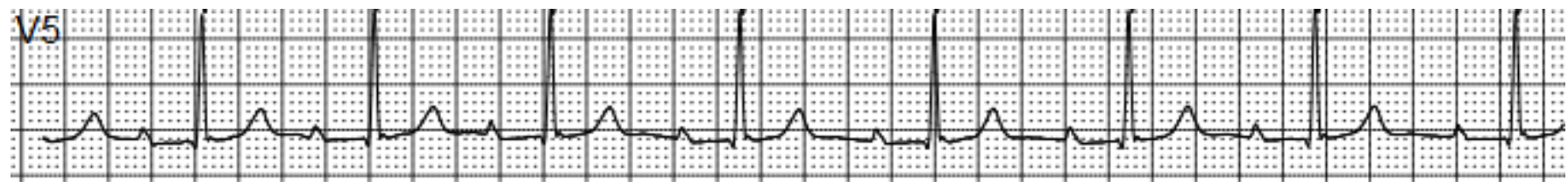

Figure 1. AV block I degree

The second degree of AV block with Wenckebach phenomenon can be recognized with gradual prolongation of $P Q$ interval and fallout of one QRS complex, which is blocked in AV node. PQ interval

observed after the blocked QRS is shorter comparatively to next ones. Then $P Q$ interval progressively increases (Fig 2). The rate of $P$ waves and QRS complexes can be 6:5, 5:4, 4:3 etc.

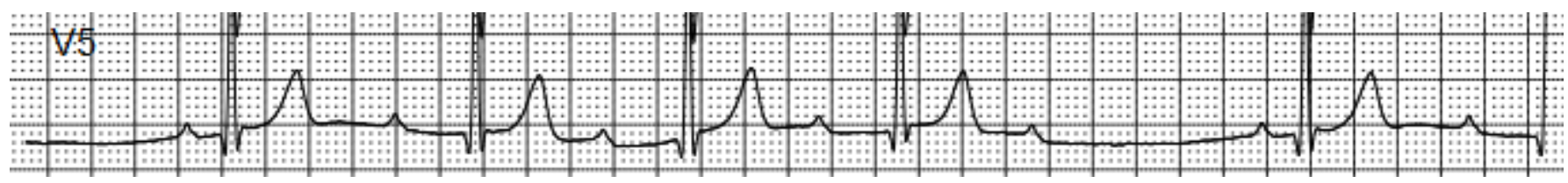

Figure 2. AV block II degree with Wenckebach phenomenon

The main feature of the second degree of AV block Mobitz type is that drop of the QRS complex appears without segment PQ prolongation (Fig.3).

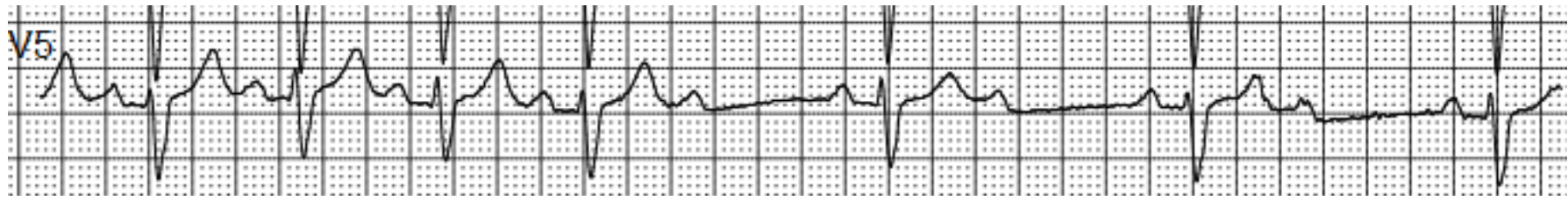

Figure 3. AV block II degree, Mobitz type

AV block II degree, 2:1 can be registered on ECG, when the rate of $\mathrm{P}$ waves and QRS complexes is 2:1, but there is no possibility to obtain how it appears. AV conduction with the Wenckebach phenomenon rate can gradually decrease to 2:1 rate or AV block 2:1 can occur according to the Mobitz type (Fig.4).

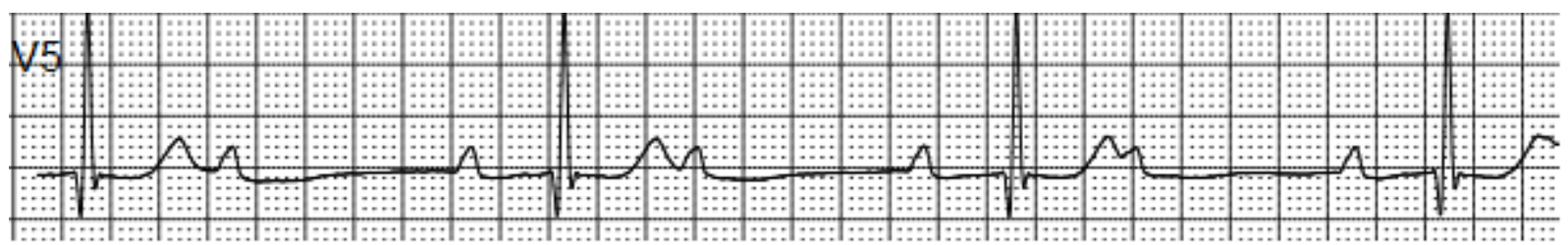

Figure 4. AV block II degree, 2:1

Address for Correspondence: Mykhaylo Sorokivskyy, Danylo Halytsky Lviv National Medical University, Lviv Regional Cardiology Center, Lviv, Ukraine; Email: msorokivskyy1@gmail.com

Received: 14.10.2019 Accepted: 15.10.2019

Copyright $\odot 2019$ Heart, Vessels and Transplantation

doi: 10.24969/hvt.2019.162 
Complete AV block is characterized by complete absence of the $P$ waves and the QRS complexes accordance. Any signs of atrioventricular conduction

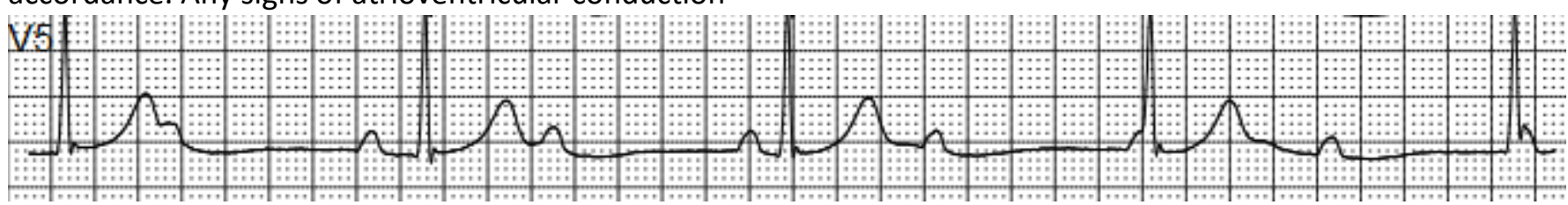

cannot be revealed on ECG. QRS complexes narrow or wide appear with own very often slow rhythm (Fig.5).

Figure 5. AV block III degree, complete

Advanced AV block II is shown on Figure 7 (Fig. 1 on page 163) and is recognized by rare episodic signs of the AV conduction. Only $5^{\text {th }}$ and $8^{\text {th }}$ QRS complexes (Fig.7) are conducted via AV node. There is no accordance between $\mathrm{P}$ waves and other QRS complexes on this ECG. AV conduction is severely disturbed in this case and only single conducted $P$ waves suggest that $\mathrm{AV}$ block is not complete.

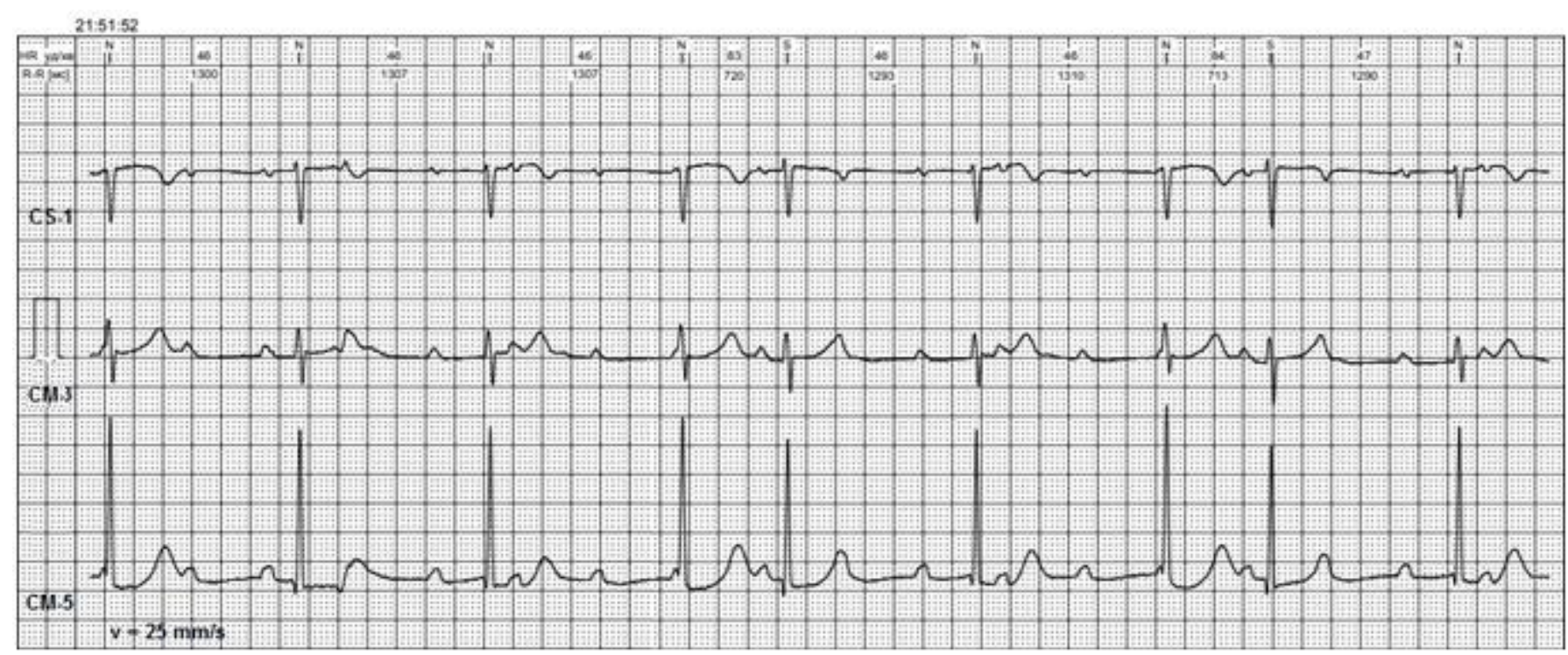

Figure 7. Fragment of the 3-channel Holter monitoring

Mykhaylo Sorokivskyy, Ulyana Chernyaha-Royko Danylo Halytsky Lviv National Medical University, Lviv Regional Cardiology Center, Lviv, Ukraine Peer-review: internal Conflict of interest: None to declare Authorship: M.S. and U.C-R. equally contributed to preparation of quiz Acknowledgement and funding: None to declare 